\title{
Green Computing- Embrace a Secure Future
}

\author{
Prof. Riyaz A. Sheikh \\ Faculty-Department of Management Studies \& Research \\ Tirpude College of Social Work \\ Nagpur(INDIA)
}

\author{
Dr. U.A. Lanjewar \\ Principal-Centre Point College \\ Nagpur (INDIA)
}

\begin{abstract}
ICT has now become an important department for the success of any organisation. Most of the businesses rely on the many benefits computers provide by using computing resources to perform a multitude of tasks, including work, research, teaching and learning. However the IT department is usually always the one department that uses the most amount of power which in turn is an excessive amount of overhead for a business as well as a source for toxic waste. Making IT "Green" can not only save money but help save our world by making it a better place through reducing and/or eliminating wasteful practices and using nontoxic materials.

While using ICT, many institutions are a source for excessive power use, excessive spending of resources, and uses many toxic materials. All of these items are bad practices and converting a company's IT department to a more streamlined green concept is far more cost effective as well as better use of resources. This paper examines the need and provides a guideline which highlights our responsibilities as computer users and encourages us to take actions that maximize the usefulness of these amazing tools while minimizing the negative consequences that may occur during their use.
\end{abstract}

\section{Keywords}

\section{Green computing, IT, ICT, toxic, E-Waste}

\section{INTRODUCTION}

\subsection{What is Green Computing?}

Green computing or green IT, refers to environmentally sustainable computing or IT. It is the study and practice of designing, manufacturing, using, and disposing of ICT efficiently and effectively with minimal or no impact on the environment. Green IT also strives to achieve economic viability and improved system performance and use, while abiding by our social and ethical responsibilities. Thus, green IT includes the dimensions of environmental sustainability, the economics of energy efficiency, and the total cost of ownership, which includes the cost of disposal and recycling. ${ }^{[8]}$ It is important to understand the need of the study of green computing. It is a tool by which global warming can be control and reduce. The Global surface temperature increased by $0.74 \pm 0.18{ }^{\circ} \mathrm{C}\left(1.33 \pm 0.32{ }^{\circ} \mathrm{F}\right)$ during the 100 years ending in 2005. Most conspicuously, according to the latest IPCC report the global surface temperature will likely to rise a further 1.1 to $6.4{ }^{\circ} \mathrm{C}\left(2.0\right.$ to $\left.11.5^{\circ} \mathrm{F}\right)$ during the twenty-first century $^{[3]}$

\subsection{Global Effect}

No matter what we do, global warming is going to have some effect on Earth. Here are the six deadliest effects of global warming.

1. Polar ice caps melting

2. Spread of disease

3. Warmer waters and more hurricanes

4. Increased probability and intensity of droughts and heat waves

5. Economic consequences

6. E-Waste

\section{NEED OF GREEN COMPUTING}

In IT department, it is observed that the people are unaware of the consequences of mishandling. It is observed that most of the computer energy is often wasteful. This is because we leave the computer $\mathrm{ON}$ even when it is not in use. The CPU and fan consume power; screen savers consume power even when the system is not in use. Insufficient power and cooling capacities can also results in loss of energy. It is observed that most of the data centers don't have sufficient cooling capacities. This results in environment pollution. This could be because of defects in Manufacturing techniques, packaging, disposal of computers and components. Another effect is because of toxicity. There are toxic chemicals used in the manufacturing of computers and components which can enter the food chain and water. According to one source, "Information Technology energy demand is growing 12 times faster than the overall demand for energy" and "Data centres emit over 150 metric tons of $\mathrm{CO} 2$ per year, and the volume is increasing rapidly. (As a point of reference, a car produces 18 pounds of $\mathrm{CO} 2$ for every gallon of gasoline it uses.)"

It is the need of the hour to educate people about the "GREEN" use of ICT. In order to promote these ideas and create standards and regulations various organizations have been formed. Many technology companies actually belong several of these to further there goals of becoming more "green".

Some of these green organizations are:

1. "The Green Grid is a global consortium of IT companies and professionals seeking to improve energy efficiency in data centres and business computing ecosystems around the globe." Board members of The Green Grid include AMD, EMC, Intel, APC, HP, Microsoft, Dell, IBM, and Oracle. ${ }^{[8]}$ 
2. The U.S. Environmental Agency is a government agency that was created to protect human health and to safeguard the natural environment. This agency also created a joint program called Energy Star with the U.S. EPA and the U.S. Dept of Energy. ${ }^{[9]}$

"The ENERGY STAR label was established to: Reduce greenhouse gas emissions and other pollutants caused by the inefficient use of energy; and Make it easy for consumers to identify and purchase energy-efficient products that offer savings on energy bills without sacrificing performance, features, and comfort." [3]

\section{AREA OF FOCUS}

It is important to understand the life cycle of computer while applying the concept of GREEN IT. This was explained with the help of following figure 1 .

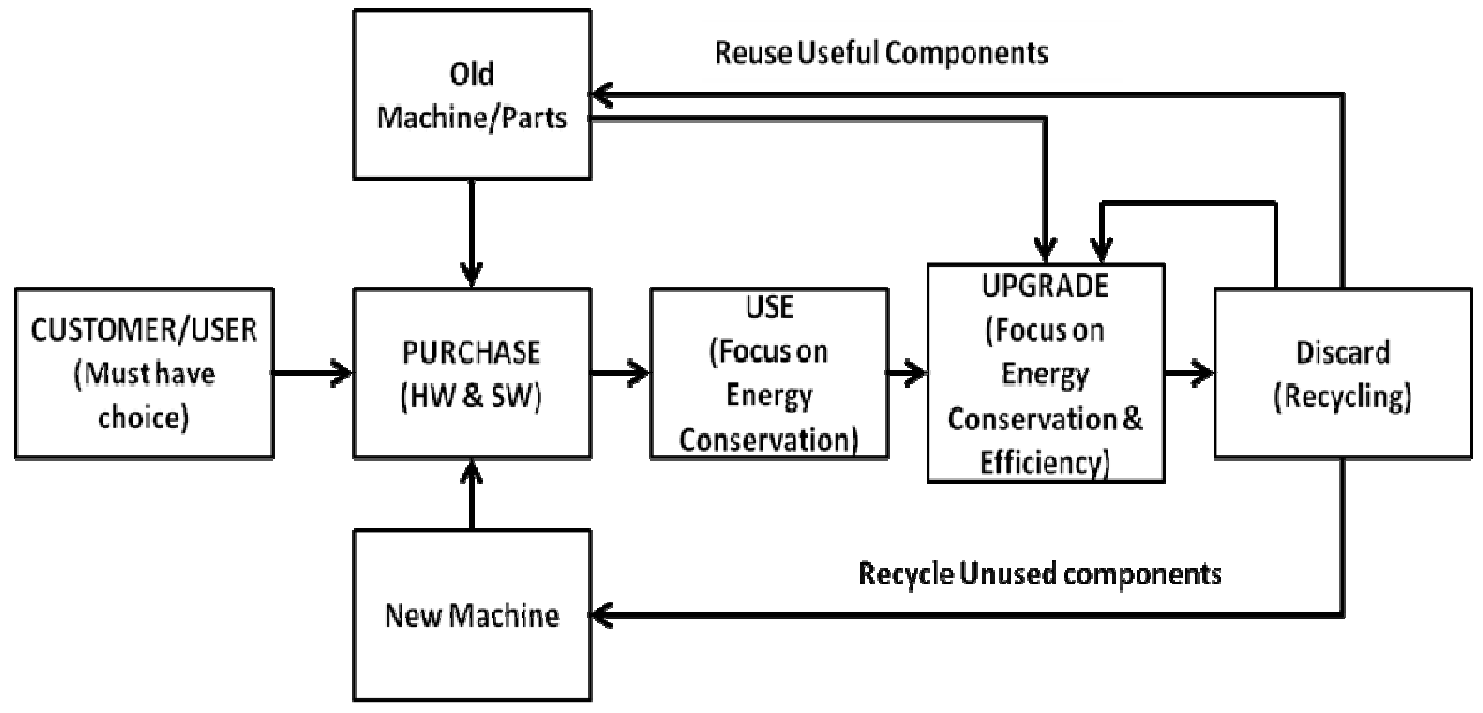

FIGURE 1: Life Cycle Approach for Green IT

From the view of a user in an organization, following are the area of focus for making the IT GREEN:

- Energy Consumption - saving energy while use

- Purchase- Responsible computer purchase

- Energy use- Energy use and efficient ways to computing.

- $\quad$ Reducing waste- Using computers to reduce the use of natural resources.

- $\quad$ Recycling - disposal considerations.

\section{ENERGY CONSUMPTION}

Between 2000 and 2010, the use of computer in business has increased significantly. Computers, monitors and printers used by staff may typically consume more than 150 watts, and a good portion of the energy consumed ends up wasted due to equipment left on when not in use. According to the Environmental Protection Agency (EPA), 30 to $40 \%$ of personal computers and printers are kept on during the night and on weekends and are left to idle as much as much as $90 \%$ of the time during the work day. ${ }^{[9]}$

Vidarbha produces most of their electricity from burning coal. Coal is one of the important natural resource. Excessive use of electricity can exhaust this resource. Being energy-conscious and buying energy-efficient computers and peripherals will help:

- Save natural resources

- Save and protect water

- Make your home / work space more affordable

- Improve air quality

- Reduce mercury emissions

\section{PURCHASING YOUR COMPUTER}

\subsection{Conserve Energy}

Before buying a new computer, be aware that many have a built-in feature that, when enabled, reduces energy consumption. When not in use, activating the computer's "stand-by" mode can reduce energy consumption by $80 \%$. "Deep sleep" mode (hibernate) offers even greater energy savings by reducing consumption by $96 \%$.

- Choose Energy Star®-compliant computers and peripherals

- Ensure that your computer's power management feature is enabled

- Select an efficient processor that meets your needsWhen you are ready to buy your next computer and minimize the environmental hazards that come with it, consider visiting the Computer Report Card, which reviews computer manufacturer's environmental commitments www.svtc.org/cleancc/pubs/2003report.htm

\subsection{Which is more efficient, a Laptop or Desktop?}

Desktop PCs are great for a home or office computer, but they use up to six times more energy than a laptop. By using appropriate power management settings on a desktop, you will save energy, but not nearly the amount you would save by using a laptop.

Laptop computers are designed to use much less energy than desktop computers - as much as $80 \%$ less. And, of course, there is one extra perk - laptops are portable. Many laptops can be hooked up to a separate full-size monitor and keyboard for use at home or in the office. ${ }^{[11]}$ 


\subsection{Upgrade Your Existing Computer}

All computers can be upgraded to some extent. By upgrading your computer, you can increase speed, memory, performance, and you can extend the life of your system and some of the components. Reuse first, and then recycle! Log on to one of the following sites to learn more about upgrading your computer:

www.memman.com

www.harddriveupgrade.com

Or, check the yellow pages under computers and computer equipment, dealers - used, or service and repair.

Note: A chip that weighs close to nothing creates a total of 89 pounds of waste, 7 of which are hazardous and uses 2,800 gallons of water. ${ }^{[12]}$

\subsection{Buying Used machines}

Save money and resources by considering the purchase of a used or rebuilt computer. Or, consider buying from other local used computer retailers that you can find in the Yellow Pages.

Note: Circuit boards weigh only 4 pounds but generate 40 pounds of hazardous waste - 280 pounds of copper sulphide ore are used to create 2.5 pounds of copper for the circuit board, using the energy equivalent to 73 gallons of gasoline - Boiling the ore to create pure copper also produces sulphur dioxide, which causes acid rain..$^{[12]}$

\subsection{Monitors - CRT vs. LCD}

The monitor accounts for about half the energy use of a typical computer desktop. Most monitors use cathode ray tube (CRT) technology. Large CRT monitors use more energy than small ones - a 17" colour monitor uses about 35\% more energy than a 14 inch colour monitor. High-resolution monitors use more energy than low resolution models.

Note: 139 pounds of waste are generated in the process of creating one monitor. ${ }^{[12]}$

\subsection{Printers - Ink Jet vs. Laser Jet}

Laser jet printers offer speed and superior quality, but consider getting a high-end ink jet printer, which costs a lot less and consumes $90 \%$ less energy. 5 Ink jet printers cannot compete with lasers when it comes to speed, but the print quality is quite good on newer models. Ink jet printer print well on used paper, so you can print drafts on the back side of old work. Colour copies are more affordable with ink jets, too ${ }^{[13]}$

Choose a printer with a duplexing mode, which prints on both sides of the paper. If you do purchase a laser printer, you can cut energy use substantially by getting a slower one. And, turn the printer off when it's not in use - laser printers draw about $1 / 3$ of their energy when they are on standby ${ }^{[14]}$

\section{Note: Laser printers use energy even when turned off. Unplug your printer when not in use.}

\subsection{Paper Choices}

Considering the type of paper you are printing on also helps conserve resources. Look for acid-free, $100 \%$ post-consumer recycled and chlorine-free paper. Such post-consumer recycled paper reduces energy consumption by $60 \%$. Using virgin paper may cost you less money, but it costs the environment so much more. One ton of virgin paper creates 60 pounds of air pollution, uses 17 trees, 7,000 gallons of water, and 3.3 cubic yards of landfill space. ${ }^{[15]}$

\subsection{CDs and Floppy Disks}

Since CDs are the most widely used for recording data for backup, transfer, or whatever the purpose, consider purchasing CDRWs, which are re-writable CDs. CDRWs can be used over and over, unlike regular CDs, which can only be burned one time. Even though floppy disks are used far less these days, it is always better to reuse when you can. One can buy recycled floppies though www.greendisk.com. GreenDisk also provides CDs with $100 \%$ recycled packaging surrounding a new disk. See the disposal section for how to recycle used media.

Note: About $40 \%$ of the heavy metals in landfills, including lead, mercury, cadmium, and other toxic materials, come from electronic equipment discards. Just 1/70th of a teaspoon of mercury can contaminate 20 acres of a lake, making the fish unfit to eat..$^{[15]}$

\subsection{And, Don't Forget About Peripherals!}

Computer peripherals also consume electricity and should be turned off when they are not being used. A power-strip with surge protection has an on/off switch, making it easy to turn off all your computing equipment at the end of the day. Many electronic devices continue to use electricity even when they are not being used and the equipment is turned off. Turning off your surge protector/ power strip will still protect your equipment from power and voltage surges.

\section{USING YOUR COMPUTER}

\subsection{Power Management}

According to EPA surveys, about $44 \%$ of all PC users do not have or do not use power-management software. For those who do have the software installed and enabled, it is still more energy efficient to shut down because computers and monitors continue to draw power even when sleeping. Some even draw power when completely shut down, so consider plugging all peripherals into one power strip/surge protector and turn that off when the computer is not in use.

Of course, it is not practical for everyone to shut down their computers when not in use. The ideal approach is to use the power management system settings to meet your specific needs. Turning on power management isn't very difficult, but some users may be confused about what the various options mean. If you need assistance, try the system's built-in "help" system. Or, log onto one of the following sites:

- www.energy-solution.com/off-equip/

- www.pcpowermanagement.com

- www.microtech.doe.gov/EnergyStar/

The Energy Star ${ }^{\circledR}$ certification program is offered by the EPA. When activated, equipment meeting the Energy Star ${ }^{\circledR}$ guidelines enters a power-saving sleep mode after a period of inactivity.

\subsection{Power Management Settings}


Follow these instructions to enable the power management feature on your computer:

PCs running Windows (2000, XP)

1. Right click on your desktop and a dialog box will appear

2. Select "properties"

3. Select "screen saver" tab

4. Select "energy saving features"

5. Select "settings"

6. Select the number of minutes you would like to keep your computer and your monitor on before they power down.

Macs (OS7.1 - OS9, OSX)

1. Click on Apple icon

2. Select "control panels" in OS9 and "system preferences" in OSX

3. Select "energy saver"

4. Select "show details" in OS9

5. Check separate timing for display sleep

6. Select the number of minutes you would like to keep your computer and your monitor on before they power down.

Note: A screen-saver doesn't really save energy? Turn your monitor off when it is not in use for more than 15 minutes.

Just how much energy can you expect to save? Here's an example: Dell Dimension (tower) uses: 106 watts on, 19 watts stand-by Dell 17" Flat Panel Monitor: 32 watts on, 4 watts stand-by Dell Inspiron 600M (Centrino): 27 watts on, 2 watts stand-by Dell Inspiron 1150 (Pentium IV): 43 watts on, 4 watts stand-by HP LaserJet 1012: 400 watts on, 1 watt stand-by

HP All-in-One 1350 (Inkjet): 14 watts on, 5 watts stand-by

\subsection{Best Practices}

Follow these tips to help conserve energy:

$>$ Do not turn on your computer or peripherals until you need to use them, and turn them off when you are finished

$>$ If it is not recommended that you turn off your computer, turn off your monitor whenever you will be away from your computer for more than 15 minutes

$>$ Enable the energy management settings on your computer, saving you money and wasted watts

$>$ Set the shortest possible time that is acceptable before your computer automatically powers down (recommended: 15 mins)

$>$ Turn off your computer and peripherals at night, on week ends, and when left unused for an extended period of time

$>\quad$ Try to plan computer-related activities so you can do them all at once, keeping the computer off at other times

$>$ Do not turn on the printer until you are ready to print

$>$ Purchase equipment with the Energy Star ${ }^{\circledR} \operatorname{logo}$

$>$ Turn off the power strip when nothing is in use because even when off, many electronic devices still draw electricity.

Note: One computer left on 24 hours a day dumps 1,500 pounds of $\mathrm{CO} 2$ into the atmosphere. $A$ tree absorbs between 3-15 lbs of CO2 annually. That means that 100-500 trees would be needed to offset these yearly emissions.

\section{REDUCING CONSUMPTION}

7.1. Paper

There are many negative impacts that result from the mass consumption of paper - money lost, pollution emitted, energy consumed, water used, landfills running over. Many of them can be avoided by using paper made from post-consumer waste, agricultural by-products, or sustainably harvested fibers. These impacts can also be avoided by reducing paper consumption by simply adjusting printing formats:

\begin{tabular}{|l|l|}
\hline$\underline{\text { From }}$ & 12 point font \\
$1.25^{\prime \prime}$ margins & $\begin{array}{l}\text { To } \\
.75^{\prime \prime} \text { margins } \\
\text { single spaced } \\
\text { two sided } \\
15 \text { page document }\end{array}$ \\
\hline double spaced & \\
100 page document
\end{tabular}

FIGURE 2: Format Printing

Reusing paper saves the energy used to make new paper - an average of 15 watt-hours of energy is used to produce a single sheet of paper - and it saves you the money of purchasing it, not to mention the economic and environmental cost of transportation from plant to user. ${ }^{[16]}$

Note: Your computer is made up of plastics, metals, glass, silicon and about 1,000 other materials and chemicals - half of which are hazardous. It contains scores of toxic materials that pose health threats to the people who produced it and to the people living near the factory where it was created ${ }^{[12]}$

\subsection{Editing}

Use the power of your software to edit on screen. For example, use the "track changes" tool in Word instead of editing from a paper copy. Also, send e-mail or transfer data files through the internet.

When delivery of a hard copy is not essential, don't print it. Finally, print completed documents in batches. This reduces "on" time and eliminates idle time.

\subsection{Printing}

If you use Microsoft Word and your printer does not allow for double-sided printing, try using "Print" and select "odd pages." Then, put the paper back in the printer on its reverse side and print again, selecting "even pages." This is especially useful for larger jobs, saving paper, money and storage space for your documents.

Note: Studies estimate that 315 to 600 million desktop and laptop computers in the US will soon be obsolete and contain a total of more than 1.2 billion pounds of lead. Discarded computers and electronics - so called e-waste - are hazardous wastes and there is no good system for safely handling them. This waste is the fastest growing portion of our waste stream, growing almost three times faster than our municipal waste stream. Less than $10 \%$ of 
discarded computers are currently recycled, and many older computers are either stored somewhere awaiting a decision or are tossed out with the trash without realizing the hazards contained in them.

Keeping all computers and consumer electronics out of landfills and incinerators is imperative if we want to protect our public health and the environment. Even recycling them is difficult because they're full of toxic materials. ${ }^{[12]}$

\section{WHEN YOU DON'T NEED IT ANYMORE}

\subsection{Re-Use}

If you are not sure what to do with your old computer, some places accept computers and monitors, which they rebuild for sale. They recycle certain parts of these electronics that cannot be salvaged during the rebuilding process. There are various organizations which accept unused computers and make them usable. For your personal equipment, there are NGO's which accept, refurbish and sell computers and monitors depending on age and processing speed. Materials not used or salvaged are recycled to the best of their ability.

\subsection{Recycling}

There are many places right here in India that will recycle that old computer for you. Hewlett Packard, Dell and several other companies have adopted a "Take-Back" recycling program, but are still only recycling about $2 \%$ of their products when compared to current sales.

\subsection{It is time to evaluate your real needs...}

Do you really need that new computer? Should you upgrade your existing computer? What about recycling it? Consider all of these questions very carefully before you make a final decision. And remember, your decision does not affect you alone.

\section{CONCLUSION}

We are not passive spectators, but active contestants in the drama of our existence. We need to take responsibility for the kind of life we create for ourselves- Nathaniel Branden, Ph.D. ${ }^{[17]}$

Make your entire organisation Green in every way possible. Understand the life cycle of IT products. Reduce as much paper as possible and recycle it when you can. Recycle the water the organisation uses by collecting rain water and filter it for sinks and drinking fountains, take drain water from sinks and water fountains and use the grey water for flushing the toilets. Encourage your employees to carpool, ride bicycles, or use any other mass transit transportation. A green roof can be a good location for a break area for employees. These are but a few small ideas you can use to make your business more Green which is good for the Environment and the stock-holders. Let's start working on it and embrace the future.

\section{REFERENCES}

[ 1 ] Baroudi, Hill, Reinhold, and Senxian (2009) Green IT for Dummies,

[ 2 ] Climate Savers Computing Initiative (2010) Retrieved from http://www.climatesaverscomputing.org/

[ 3 ] Energy Star Program (2010) Retrieved from http://www.energystar.gov/

[ 4 ] http://www.theglobalwarmingstatistics.org/globalwarming-essays
[ 5 ] Microsoft: Green IT taking the first step (2010) Retrieved from http://www.microsoft.com/environment/our_commitme nt/articles/green_guide.aspx

[6] Recycle-it America (2010) Retrieved from http://www.recycleitamerica.com/

[ 7 ] San Murugesan, "Harnessing Green IT: Principles and Practices," IEEE IT Professional, January-February 2008, pp 24-33.

[ 8 ] The Green Grid (2010) Retrieved from http://www.uh.edu/infotech/news/story.php?story_id=1 30

[ 9 ] Ryan, John C. \& Durning, Alan T. Stuff: The Secret Lives of Everyday Things. 1997 